\title{
From Cautious Enthusiasm to Profound Disenchantment Ernest Nagel and Carnapian Logical Empiricism
}

\author{
Thomas Mormann \\ Department of Logic and Philosophy Science \\ University of the Basque Country UPV/EHU \\ Donostia-San Sebastian, Spain \\ thomasarnold.mormann@ehu.eus
}

\begin{abstract}
In this paper I'd like to study the complex relation between logical empiricism and American pragmatism examining the case of Ernest Nagel. More precisely, I want to explore some aspects of Nagel's changing attitude towards the "new" logical-empiricist philosophy that arrived in the US in the 1930s. In the beginning, Nagel welcomed logical empiricism almost wholeheartedly. This early enthusiasm did not last. Nagel's growing dissatisfaction with the Carnapian version of logical empiricist philosophy was clearly expressed in his criticism of Carnap's inductive logic and more generally in his last book, Teleology Revisited and Other Essays in the History and Philosophy of Science, where he criticizes Carnap's philosophy of science in general as ahistoric and non-pragmatist. It is argued that Carnap and Nagel represented opposed possibilities for how the profession of a philosopher of science could be understood: Carnap, as a "conceptual engineer", was engaged in the task of inventing conceptual tools for a better theoretical understanding of science, while Nagel is better characterized as a "public intellectual" engaged in the more general practical project of realizing a more rational and enlightened society.
\end{abstract}

Keywords: Logical Empiricism; American Pragmatism; History of Science; Rudolf Carnap; Ernest Nagel

\subsection{Introduction}

The relation between logical empiricism and American pragmatism is one of the more difficult problems in the history of philosophy. ${ }^{1}$ This relation cannot be described as a pointlike event; rather, it was a process that evolved for various decades. For some time, a variety of contradicting narratives about this difficult and complicated issue have been espoused.

\footnotetext{
${ }^{1}$ For the sake of simplicity let us assume in the following that there were only two parties of the encounter- the logical empiricists and the American pragmatists. Actually, this is a simplified description of the situation: Reality was more complicated. Science-oriented philosophy in US comprised more than pragmatism, there was an important philosophical current called "(Columbia) naturalism", “contextualistic naturalism", or "realism”, which was closely related to but different from genuine pragmatism; cf. Jewett $(2011,2012)$ and Kuklick (2001). Perhaps it may even be expedient to speak of various different "pragmatisms" at that time; cf. Tuboly (2021).
} 
In this paper, I do not want to tell another global story about this issue. Rather, I would like to take a more local perspective and concentrate on the details that concern the vicissitudes of a philosopher who played an important role in the encounter between logical empiricism and American pragmatism, namely, the American philosopher Ernest Nagel (1901-1985). Although Nagel was one of the most influential American philosophers of science in the middle of the 20th century, he has been unduly ignored in recent debates on the relation between logical empiricism and pragmatism.

In this paper, I want to explore some aspects of Nagel's changing attitude towards the "new" logical-empiricist philosophy arriving from Europe at the shores of the New World in the 1930s. Like many other scientifically minded American philosophers in the beginning, Nagel welcomed the logical empiricists whole-heartedly as allies in the project of the "cooperative, intensive cultivation of the methods of the sciences with the help of the most advanced tools of modern logic" (Nagel 1940, p. 69). ${ }^{2}$ He was one of the younger American philosophers who had visited with the proponents of European logical empiricism in the early 1930s before they were forced to emigrate to the US or elsewhere. Moreover, together with Charles Morris and others, he hosted many European emigrants when they had to build up a new life in US. As I want to show, this early cautious enthusiasm did not last. At the end of his philosophical career in the late 1970s, Nagel's early positive attitude towards logical empiricism (essentially characterized by Carnap's philosophy) had been replaced by a much more reserved attitude to put it mildly.

Thus, instead of a global narrative about the general relation between two multifaceted philosophical currents, I propose to pursue a kind of longitudinal analysis concentrating on one individual philosopher who played an important role in the encounter of the two movements. This is enough to refute some of the sweeping narratives on this issue presently propagated in the literature, or so I want to argue.

European logical empiricism was present on the American scene, in one way or another, for approximately 50 years, from approximately the 1930 s to the $1980 \mathrm{~s}^{3}$ Nagel's career as a professional philosopher comprised roughly the same period. This fact may be

\footnotetext{
${ }^{2}$ Certainly not all, however. For instance, according to Jewitt (2011, p. 91), in 1948, J.H. Randall, one of the proponents of Columbia naturalism, still described Carnap as "a Prussian systematizer" who was "relatively insulated from the main currents of American experience and thought". Indeed, in the 1940s many pragmatists opposed Carnap-style semantics.

${ }^{3}$ Herbert Feigl came to America in 1931, Carnap passed away in 1970. Feigl and Hempel, often characterized as the "last logical empiricists", lived until 1988 and 1997, respectively.
} 
taken as evidence that he may well serve as a (more or less reliable) individual witness of the events that took place in this historical period.

The organization of the paper is as follows. To set the stage, in the next section, I briefly recall some of the main contemporary narratives that are en vogue to describe the complex relationship between logical empiricists and American pragmatists in the second third of the 20th century. All these narratives are of a global character-they all paint the relation between the two philosophical currents with a broad brush, hardly taking into account the vicissitudes of individual philosophers. As I want to show, they all have difficulties to deal adequately with the case of Nagel. Indeed, he turns out to be an interesting challenge for all existing narratives of the relation between logical empiricism and American pragmatism.

In the third section, I will deal with Nagel's early work that exhibits what may be characterized as a cautious enthusiasm towards the "new logical empiricist philosophy". In particular, Nagel's contribution, "Charles S. Peirce: Pioneer of Empiricism” (Nagel 1940), at the 5th International Congress for the Unity of Science in Harvard is considered here.

The topic of Section 5.4 is Nagel's growing dissatisfaction with Carnap's version of logical empiricist philosophy in the following decades. This dissatisfaction was clearly expressed in Nagel's criticism of Carnap's inductive logic (Nagel 1963) and more generally and more explicitly in his last book, Teleology Revisited and Other Essays in the History and Philosophy of Science (Nagel 1979). ${ }^{4}$ There, he criticized very harshly Carnap's philosophy of science in general as ahistoric and outdated.

One of the distinctive features of Nagel's philosophy of science is the emphasis that he put on the role of the history of science for philosophy of science. Compelling evidence for this attitude is seen in his works on the history of geometry and algebra that, to the present day, are considered valuable contributions to the history of ideas. This aspect of Nagel's philosophy of science is treated in Section 5.5. Finally, in Section 5.6, we briefly discuss the question of who the audience of philosophy of science is. One may say that Carnap and Nagel represented opposed possibilities for how the profession of a philosopher of science may be understood: As will be discussed Carnap as a "conceptual engineer" was engaged in the task of inventing the conceptual tools for a better understanding of science as a complex

\footnotetext{
${ }^{4}$ This book contains (among some other earlier texts of Nagel) his Dewey Lectures, which he delivered at Columbia University in 1977. These may be considered a kind of summa of Nagel's philosophy and history of science.
} 
endeavor in itself, while Nagel was to be considered more of a "public intellectual" engaged in the project of realizing a more rational and enlightened society.

\subsection{The Encounter of Logical Empiricism and American Pragmatism: A Potpourri of Narratives}

The encounter between European logical empiricism and American pragmatism was a complex and multifaceted event of the history of philosophy in the 20th century. Perhaps the simplest narrative of this event is Richard Rorty's version of the (temporal) replacement of home-spun American pragmatism by logical empiricism. It goes like this:

\footnotetext{
Along about 1945, American philosophers were [...] bored with Dewey, and thus with pragmatism. They were sick of being told that pragmatism was the philosophy of American democracy, that Dewey was the great American intellectual figure of their century, and the like. They wanted something new [...] What showed up [...] was logical empiricism, an early version of what we now call "analytic philosophy".

The incursion of this kind of philosophy was [...] a mixed blessing. [...] [I]t represented a temporarily fruitful confusion of a very good idea (that language was a more fruitful topic for philosophical reelection than experience) with a couple of rather bad ones (that there was something worth preserving in empiricism; [...]). (Rorty 1995, p. 70)
}

Fortunately, according to Rorty, the eclipse of pragmatism did not last for long. With Rorty himself actively engaged in the project, the eclipse was overcome in the next decades. At least, this is the story that Rorty wanted to make his audience believe:

\footnotetext{
The narrative I have tried to construct in my books tells how the bad ideas gradually, in the course of the 1950s and 1960s, got filtered out and thus made it possible for pragmatism to get a new lease on life by undergoing linguistification. (Rorty 1995, p. 70)
}

A different version of this eclipse narrative has been offered by Scott Soames. He skips the second half of Rorty's story, i.e., for him the alleged resuscitation of classical pragmatism in the form of (Rortyan) neo-pragmatism the heroes of which were Dewey, Wittgenstein, and Heidegger, does not exist. In his narrative, even Dewey does not occur (to say nothing about Wittgenstein and Heidegger). According to Soames, the only contribution that American pragmatism had to offer to the new analytical wave was the logical achievements of Peirce and C.I. Lewis. As minor figures in the transition from the pre-analytic to the analytic period 
in American philosophy, Morris Cohen and Nagel are briefly mentioned (Soames 2008, pp. 451-452).

Not all people agree with the stories told by Rorty and Soames. Cheryl Misak, for instance, in her book The American Pragmatists (Misak 2013), completely discards the replacement or eclipse narrative. According to her, the logical empiricist invaders were assimilated by American pragmatism in such a way that they hardly left any trace:

\footnotetext{
One thing, however, should be clear from my account of the fortunes of pragmatism. Those who would argue that pragmatism was bullied into the backwaters by the logical empiricists ... have their intellectual history wrong. Not only were there strong connections between pragmatism and logical empiricism, but the logical empiricists drifted closer and closer to their pragmatist cousins until the views were almost indistinguishable. (Misak 2013, p. 254; original emphasis)
}

These incompatible narratives may leave the reader somewhat perplexed, since even the simple question "At the end of the day, who replaced whom?" does not find a unanimous answer. Even less satisfying is what this potpourri of narratives has to offer for the task of determining Nagel's position in this changing conceptual landscape. As usual, Rorty's overall general pastiche is of no use for discovering any detail. Soames mentions Cohen's and Nagel's early contributions to a (broadly understood) naturalist and empiricist philosophy of science but ignores Nagel's later criticism of Carnapian logical empiricism. Misak's assimilation narrative entails that Nagel should have recognized the later Carnap as a fellow pragmatist. However, as will be shown in the next section, this was not the case. Rorty, Soames, and Misak offer competing global narratives about the question of how the evolving relation of logical empiricism and American pragmatism may be understood.

The following two proposals of Alan Richardson and Thomas Uebel are of a somewhat different nature. These authors deal with some more specific aspects of the encounter of the two movements that mainly concern not logical empiricism and American pragmatism in general but concentrate their attention on a small group of individuals. Nevertheless, also for them Nagel's case is a challenge.

Richardson's focus is on Carnap, Lewis, and Dewey. According to Richardson (2007), the emigration to America and the contact with American pragmatists led Carnap to adopt a kind of sui generis pragmatism. As Richardson points out, Carnapian pragmatism must be distinguished from "genuine" American pragmatism of, say, Dewey or Lewis. That Nagel did not recognize the later Carnap's philosophy as pragmatism may be read as a 
confirmation that "Carnapian pragmatism" was not "genuine" or "ordinary" American pragmatism. Indeed, according to Richardson, the two versions of pragmatisms were essentially different:

[T]he key features of Carnap's version of pragmatism are not features his pragmatism shared with the leading American pragmatists of his era. In particular, both Dewey and Lewis wanted to ground their pragmatism in an account of human nature, ... [A]t the end of the day, it is the difference over methodological naturalism that undergirds the difference between Carnapian pragmatism and the pragmatism of Lewis and Dewey: Lewis and Dewey both need and think they can have a place in philosophy to speak of the proper nature and interests of humanity; Carnap has no such need and no such place. Richardson (2007, p. 312)

Thus, if Richardson is right (I believe he is), the case of Carnap refutes Misak's just mentioned sweeping thesis that "the logical empiricists drifted closer and closer to their pragmatist cousins until the views were almost indistinguishable." As will be shown in more detail in section 5.4, also Nagel did not see Carnap as someone who had drifted towards pragmatism. Even more, he denied the later Carnap's philosophy the predicate of pragmatism. In sharp contrast, other European empiricists, such as Frank, Neurath, and Hempel, were considered by him as fellow pragmatists.

Another proposal for understanding the evolution of logical empiricism in America has been proposed by Uebel. His thesis is

that we can ascribe to [the members of the left wing of the Vienna Circle] the conception of a [...] "bipartite metatheory", a conception of philosophy of science as comprising both formal-logical and empirical investigations. [...] This conception constitutes the "unified science" alternative to Moritz Schlick's Wittgensteinian conception as meaning determination. (Uebel 2012, p. 117)

The bipartite metatheory seems to offer an elegant and ecumenical ("tolerant") way of doing a philosophy of science that everybody might feel comfortable with. Indeed, Carnap may be characterized as a partisan of such a theory. In a letter to Robert S. Cohen, he described the task of such a bipartite metatheory as follows:

For a total (not only logical) theory and analysis of knowledge and science, it is certainly very important to take into account also activities, including (1) the practical behavior of scientists in their research work (this may include pragmatics but goes far beyond it), and (2) the ways in which science is of help in all fields of practical life. I have myself not made any investigations of 
these kinds; but this does not mean that I regard them as less important. (Cohen 1963, p. 150; quoting from a letter of Carnap written to Cohen dated 12. August 1954)

Cohen was less than fully convinced by Carnap's answer and objected: "But what is the status of a purely logical analysis of knowledge in a total theory of scientific knowledge, once pure syntactic and pure (formal) semantic reconstructions are left behind?" (ibid.)

Carnap seems to have assumed that the logical and the non-logical ingredients of a "total theory" of knowledge and science can be juxtaposed and put together in such a way that they form a conceptual whole. How the purely logical and the non-logical parts of the total theory fit together, how they interacted with each other (if at all), was not a problem for him. Not all of his fellow philosophers were able to conceive of the issue in such a relaxed manner. For instance, Nagel was unable to see the conceptual unity allegedly underlying the two components of the bipartite metatheory. He came to the conclusion that Carnap's version of philosophy of science was a deadlock, while he considered philosophers such as Frank, Hempel and others to be kindred spirits.

More generally, Nagel is a problem for all existing narratives that aim to explicate the complex relation of logical empiricism and pragmatism: Nagel is a problem for Misak's drifting thesis, since he would have vigorously denied that Carnap had drifted towards genuine pragmatism. Nagel has been a challenge for Rorty's version of the eclipse narrative because, until the end of his life, he stuck to the thesis that science is the basis for a humane and liberal civilization (Nagel 1979, p. 10). Very probably, Nagel would not have subscribed to Richardson's thesis that Carnap's later philosophy of science can be characterized as a kind of pragmatism. Of course, one may contend that Nagel simply got it wrong. However, perhaps this is a solution to the problem that is slightly too simple to be right.

\subsection{Cautious Enthusiasm}

In 1939, the Fifth International Congress for the Unity of Science took place in Harvard/Massachusetts. Nagel was one of the congress participants. He took this opportunity to remind participants of the centennial anniversary 1839 of Peirce, presenting Peirce as a "pioneer of empiricism", who had anticipated many of the insights that contemporary American pragmatism and the empiricism of the Vienna Circle had obtained independently from each other. For Nagel, this kind of convergence (which often occurred in science) was to be considered evidence that some measure of truth had been attained: 
It is therefore a happy sign that so many of the central ideas of the present movement have been independently developed on both sides of the Atlantic. One is not minimizing the contributions of the Vienna Circle in pointing out that many of its recent views have been taken for granted for some time by American colleagues, largely because the latter have come to intellectual maturity under the influence of Peirce (Nagel 1940, pp. 69-70).

Were [Peirce] still among us he would surely have endorsed the happy marriage of the cultivation of logic and the empirical temper which distinguishes this movement, and he would have joined hands with us in furthering the quest for and the understanding of progressively more adequate tools of inquiry (Nagel 1940, p. 80)

Presenting Peirce as the founding father of empiricism required, of course, a considerable amount of philosophical surgery on the body of Peirce's philosophy. ${ }^{5}$ The young Nagel had no qualms about doing just this. Moreover, according to Nagel, the Vienna Circle's logical empiricism was an expedient tool for improving the central notion of Peirce's pragmatism:

\footnotetext{
"Peirce's own formulation of the pragmatic maxim leaves much to be desired in the way of explicitness and clarity; and more recent formulations, such as those by Professor Carnap and others, have the same general intent but superior precision. (Nagel 1940, p. 73)
}

Regrettably, Nagel never pointed out more precisely where Carnap had achieved such a remarkable deed, and Carnap never boasted to have done it. Thus, it remained unclear exactly where Carnap had proposed an improved version of Peirce's pragmatic maxim, to say nothing about the issue of whether he had faithfully followed such a maxim in his own philosophical work.

\footnotetext{
5 To render plausible this claim, one does not need a subtle interpretation of Peirce's thought nor a detailed elucidation of what exactly the logical empiricists of the Vienna Circle understood by "metaphysics". It should be enough to read the following passage from the later Peirce's The New Elements of Mathematics (1904) and to imagine how the arch-logical empiricist Neurath would have reacted to it: "What we call a "fact" is something having the structure of a proposition, but supposed to be an element of the very universe itself. The purpose of every sign is to express "fact,", and by being joined with other signs, to approach as nearly as possible an element of the very universe itself. The purpose of every sign is to express "fact," to determining an interpretant which would be the perfect Truth, the absolute Truth, and as such ... would be the very Universe. .... We may adopt the word entelechy [from Aristotle] to mean the very fact, that is, the ideal sign which should be quite perfect, and so identical, - in such identity as a sign may have, with the very matter denoted united with the very form signified by it. The entelechy of the Universe of being, then, the Universe qua fact, will be that Universe it its aspect as a sign, the "Truth" of being. The "Truth,", the fact that is not abstracted but complete, is the ultimate interpretant of every sign." (Peirce 1976, 239/240)
} 
Although Nagel's thesis that Carnap had the merit of having improved Peirce's pragmatic maxim may sound slightly overstated, to put it mildly, Nagel was not the only one who claimed a profound affinity between logical empiricism and American pragmatism. Much later, a fellow empiricist of Carnap, Philip Frank, confessed that he had had a similar lightning recognition long ago even before the two had arrived in America:

\footnotetext{
When I read [Carnap's Aufbau] it reminded me strongly of William James's pragmatic requirement, that the meaning of any statement is given by its "cash value," that is, by what it means for human behavior. I wrote immediately to Carnap, "What you advocate is pragmatism. This was as astonishing to him as it had been to me. We noticed that our group [...] had reached conclusions by which we could find kindred spirits beyond the Atlantic in the United States. (Frank 1949, p. 33)
}

In recent years, many different and quite sophisticated interpretations of Aufbau have been proffered; none of them, however, confirms Frank's reading of Carnap's opus magnum. Be this as it may, there can be no doubt that in the 1930s, members of both groups were strongly engaged in the project of bringing together the two philosophical movements. Even Carnap may have appeared as someone who had a keen interest in the project of $t$ logical empiricism and American pragmatism joining forces. In Testability and Meaning (Carnap 1936-37), he jettisoned unnecessary philosophical ballast that hindered a closer alliance with pragmatism: First, he pointed out that methodological solipsism should not be considered the only possible solipsism and not even the best interpretation of the Aufbau. A fortiori, in no way should the logical empiricist philosophy of science be considered as being committed to methodological solipsism in general. Second, he abandoned the overly strong and unrealistic concept of (complete) verification, replacing it with (gradual) confirmation. Testability and Meaning is often taken as evidence for the emergence of a "new" flexible Carnapian logical empiricism that subscribed to some essential philosophical theses of American pragmatism. A closer look reveals that this apparent assimilation was far from complete.

Carnap complied with the pragmatist doctrine only on one point, namely, that the absolute verification of synthetic assertions was impossible, and thus, one had to be content always with a more or less complete confirmation. Other essential, possibly anti-pragmatic, ingredients of Carnap's logical empiricism did not change after he came into contact with American pragmatism.

From early on, Nagel was well aware of certain possibly non-pragmatic aspects of Carnap's philosophizing. This was already evidenced in Nagel in 1940. On the one hand, he 
praised the Viennese philosopher as a kind of contemporary reincarnation of Peirce who had formulated Peirce's "pragmatic maxim" in a more precise and better way than Peirce himself; on the other hand, he criticized Carnap — without explicitly mentioning his name-for not complying with the standards that Peirce had already set forth for a good pragmatist. Thus, from the very beginning, Nagel's enthusiasm for Carnap's logical empiricism must be characterized as a reserved or cautious enthusiasm. More precisely, in the early 1940s, Nagel's reservations concerned the question of whether Carnap's emerging semantics were fully compatible with a truly empiricist philosophy of science:

\footnotetext{
Some have suspected, perhaps unjustly, that the recently inaugurated discipline of semantics will open wide the door for the rehabilitation of Bolzano's Saetze-an-Sich, Meinong's objectives, Russell's subsistents, and allied conceptions of the referends of signs. [...] I think it would be a retrograde step if modern logical empiricism were to revive them in a new form; for the great strength and promise of the movement has been its interpretation of the abstract in terms of the concrete, and its resolute turning from speculations which have no ascertainable consequences in issues of observable fact. I can think of no better way to still these suspicions than by placing the study of semantics into a behavioral context, and by instituting an analysis of such key semantic terms as "designation" and "truth" as used in specific contexts, in order to reveal the modes of action they signify. (Nagel 1940, pp. 76-77)
}

Obviously, Nagel considered himself to be one of those "who suspected...". ${ }^{6}$ His suspicion was confirmed a few years later when Carnap published his groundbreaking Introduction to Semantics (Carnap 1942). This is evident by Nagel's review of this work in Nagel (1942). Carnap was at pains to dispel the concerns that his "empiricist friends" had with respect to semantics. He wanted to convince them that semantics were empiristically innocent. For this purpose, he published Empiricism, Semantics, and Ontology (ESO) in 1950 (Carnap 1950). He argued that semantics are empiristically harmless. Now, the interesting point is the following: In 1954 (i.e., four years after the publication of ESO), Nagel considered it appropriate to republish the paper of 1940 in which he had voiced empiricist concerns with respect to semantics. At that time, Nagel certainly had taken notice of ESO, which had appeared in 1950. Nevertheless, he stuck to his 1940 paper. This evidence indicates that he did not accept Carnap's defense of semantics in ESO. Rather, he stuck to his original

\footnotetext{
${ }^{6}$ Another prominent logical empiricist who suspected that Carnap's "semantic turn" was a move away from true empiricism was Neurath, who severely criticized Carnap in their correspondence in the 1940s (cf. Mormann 1991). The quarrel concerning semantics led Carnap and Neurath almost to the breaking of their friendship. For some details, see the recently published letters of Carnap and Neurath in Cat and Tuboly (2019).
} 
criticism that Carnapian semantics was suspicious from an empirical point of view.

In the sequel, Nagel felt no inclination to revise his verdict. This is seen by the fact that he published his criticism of Carnapian semantics twice without any change, although Carnap had seriously attempted to dissolve the empiristically and pragmatically founded doubts concerning his semantics.

Let us return to Nagel and his approximation of the new logical empiricist wave. In 1939, he published one of the early successful contributions to Neurath's International Encyclopedia of Unified Science, namely, the monograph The Principles of Probability (Nagel 1939). The Principles of Probability became a well-recognized standard work and could be considered an example of a successful collaboration between logical empiricism and pragmatism in the context of Neurath's Encyclopedia of Unified Science. Nagel intended to take Peirce's pragmatism as a framework for a genuinely pragmatist approach to probability. In the course of time, it turned out that Nagel's conception was essentially different from that of Carnap and Reichenbach. ${ }^{7}$

Nagel's Principles of Probability intended to satisfy all requirements that a good unifying item of the International Encyclopedia of Unified Science should satisfy. Nagel based his considerations on the founding fathers of American Pragmatism, Peirce and Dewey, but also mentioned Carnap's then quite recently published Testability and Meaning and Frank's Das Kausalgesetz und seine Grenzen. Moreover, he brought Morris' trisection of syntax, semantics, and pragmatics into play, characterizing Principles as a contribution that was relevant for its semantics and pragmatics of the concept of probability and not for its syntax.

Thus, at least on the surface, The International Encyclopedia of Unified Science presented itself as a successful model of collaboration between logical empiricism and American pragmatism. In the official press announcement of the International Encyclopedia that was published in the volumes of all monographs of the first volume Foundations of the Unity of Science, the editors pointed out that the collaborators of the encyclopedia might have different points of view but that all agreed in considering the unity of science as the ideal aim of their efforts:

They agree that any form of speculation other than that recognized in science has to be eliminated they stress the importance of logical analysis in various fields and in taking into account the

\footnotetext{
${ }^{7}$ On a detailed presentation of Nagel's view on probability and his monograph in the Foundations of the Unity of Science, see Galavotti's contribution to the present volume.
} 
historical development of scientific concepts and regulative principles. Such collaborators include, for instance, persons stemming from the Vienna Circle, from the Berlin group of scientific philosophers, from the Polish school of logicians, from the group centering around Scientia and the Centre de Synthèse, as well as representatives of American pragmatists, the English analytical school, French conventionalism, [...].

(Foundations of the Unity of Science)

This description of a peaceful and harmonious collaboration of the various groups was - of course - a highly idealized picture of what truly happened. Behind the curtain, the activity of the proponents often could not be described as very harmonious (cf. Reisch 2006, Dahms 1999). In particular, there were heavy quarrels over who should be the author for the piece on probability and induction. Originally, Reichenbach was chosen as the author for this item, but for several reasons, this was not realized (see Dahms (1999) for details). The clash between Nagel's and Carnap's conceptions of probability broke out only later in the 1950s and 1960s, since in the 1940s, Carnap's ideas on probability and induction were still in an embryonic state. Hence, Nagel's empiricist-pragmatist piece seems to have pleased everybody (with the possible exception of Reichenbach). It may have even been considered as evidence that Charles W. Morris's program of a synthesis of formalism, pragmatism, and traditional empiricism that combined the virtues of these accounts while avoided their shortcomings was feasible. ${ }^{8}$ The idyllic picture of a fruitful collaboration of European logical empiricism and American pragmatism that the Encyclopedia project (and more generally, Morris's Paris program) might have offered to a superficial observer in the 1940s did not last; with respect to the issue of probability and induction, it would turn out to be an illusion only a few years later.

\subsection{Alienation and Disenchantment}

When exactly Nagel's disenchantment with orthodox logical empiricism began is hard to say. Although in his contribution to the Fifth International Congress for the Unity of Science 1939 in Harvard, he described American pragmatism as being in full harmony with logical empiricism, even though at that time, Nagel was not a dyed-in-the-wool logical empiricist.

\footnotetext{
${ }^{8}$ Morris had sketched his program of a comprehensive, practice-oriented scientific philosophy already at the International Congress of Unified Science in Paris 1935. He published a more elaborated version two years later in his booklet Logical Positivism, Pragmatism and Scientific Empiricism (Morris 1937). Against the overly narrow logical empiricist understanding of philosophy as the syntax of the language of science (that Carnap had propagated) Morris argued for a "scientific pragmatism" that comprised four levels: (1) Philosophy as Logic of Science, (2) Philosophy as Clarification of Meaning (Peirce), (3) Philosophy as Empirical Axiology (Dewey), and (4) Philosophy as Empirical Cosmology (Whitehead).
} 
This is shown by his work on the philosophy of mathematics around the same time the logical empiricists arrived in the New World (Nagel 1935/1979, 1939/1979). In this work, Nagel ascribed to the history of science a much more prominent role for the philosophy of science than orthodox logical empiricists would have been prepared to swallow. This issue will be treated in more detail in the next section.

In any case, a profound alienation between the philosophical outlooks of Carnap and Nagel is clearly documented in Nagel's contribution to the Schilpp volume dedicated to Carnap (Schilpp 1963) and Carnap's rejoinder to it. Nagel's criticism of Carnap's inductive logic is to be considered much more than a disagreement between fellow philosophers who considered each other to belong to the same movement. ${ }^{9}$ Moreover, Nagel's "most ungracious essay" (Nagel 1963, p. 825) cannot be dismissed as an insulated, perhaps only temporal disagreement concerning some technical details. Nagel republished it in his last book, apparently considering it an important piece of his philosophical legacy. ${ }^{10}$ Nagel rejected Carnap's conception of probability for fundamental reasons. According to him, Carnap's account of probability and induction had little to do with the way these concepts were used in common-day life and the sciences. As he put it:
[...] if the major criticisms advanced in [this essay] hold water, it shows that despite the remarkable constructive power and ingenuity Carnap has brought to the reconstruction of inductive logic, he has not resolved the outstanding issues in the philosophy of induction, and his general approach to the problems is not a promising one. (Nagel 1963, p. 825)

Carnap's answer to Nagel's politely formulated, but radical, critique was unmistakable:
I am sorry that my overall reaction to the essay by my dear old friend Ernest Nagel could not be more positive. My convictions on the possibility and the nature of inductive logic, acquired in many years' work and vindicated by constant reexamination, can only be shaken by strong arguments (Carnap 1963, p. 995)

In plain English, then, for Carnap, Nagel had failed to bring forward "strong arguments"

\footnotetext{
${ }^{9}$ Schilpp (1963) was published with a long delay. Hence, it may seem plausible to assume that Nagel's contribution is the result of work that can be traced back well into the mid-1950s.

${ }^{10}$ Nagel's alienation and disappointment with orthodox logical empiricism as evidenced by Nagel (1979) has been ignored in the secondary literature: Limbeck-Lilienau (2012) and Misak $(2008,2013)$ do not mention Nagel (1979) at all. This holds true, of course, for Uebel (2016), since this paper only deals with the early years of the relation between the Vienna Circle and American pragmatism.
} 
against the former's inductive logic. ${ }^{11}$ Nagel was not impressed by Carnap's harsh criticism. On the contrary, he flatly ignored it and stuck to his position until the end of his life. Almost ten years after Carnap's death, he re-published his verdict, put forward in Schilpp (1963) without any change or any further explanation. Thus, it may be considered his last word on Carnap's inductive logic, which some, Carnap himself among them, considered to be the flagship of his philosophy of science. Nagel was not just anybody in the logical-empiricist community. After all, he was the author of The Principles of Probability Theory (Nagel 1939), i.e., logical empiricism's official monograph on probability and induction, in The International Encyclopedia of Unified Science.

At the end of his philosophical career, Nagel's critique of Carnapian logical empiricism was no longer confined to Carnap's inductive logic. Its target had been widened and become Carnap's philosophy of science in general. In one of Nagel's introductions (1979), he singled out Carnap's version of the logical empiricist philosophy of science, calling it obsolete in its entirety. Compared with the classical pragmatisms of Peirce and Dewey on the one hand and other versions of logical empiricism such as those of Frank and von Mises, Carnap's orthodox logical empiricism came off the worst. Pointing out that the philosophy of science of the philosophy of the logical empiricists Frank and von Mises was not formalist or ahistoric, Nagel blamed the Carnapian philosophy of science as being responsible for the recent rise of a new orientation in the philosophy of science that was skeptical of the efficacy of the scientific method for attaining genuine knowledge:

\begin{abstract}
Much of the animus of the "new orientation" in the philosophy of the science is directed against the alleged ahistorical character of the "orthodox approach"; against the latter's supposed claim that the observational evidence for a scientific theory can be assessed by using the rules of a formal calculus; [...] These characterizations of the "old philosophy of science" are conceivably true of some philosophers in this category (for example, Rudolf Carnap). These characterizations are a caricature of most of the older generation of writers on the subject (for example, C.S. Peirce, Josiah Royce, John Dewey, M.R. Cohen, or P.W. Bridgman), and they are not even true of some of Carnap's fellow logical positivists (such as Philipp Frank or Richard von Mises). Unlike Carnap, none of these thinkers subscribed to an ahistorical evaluation of the evidence for a
\end{abstract}

\footnotetext{
${ }^{11}$ Nagel was not the only contributor who was rebuked by Carnap in this way: According to Carnap, Popper had — once again — completely misunderstood him, Putnam's claim that Carnapian inductive logic was impossible was simply dismissed. Carnap did not disagree, however, with Kemeny, who put forward the thesis that "the problem of induction [...] [was] certainly the central issue in any philosophy of science" and ended with the hymnical conclusion that "we must class Carnap's contribution to the problem of induction among the greatest achievements of modern Philosophy (sic)" (Kemeny 1963, pp. 711, 737). Recent assessments of the feasibility of an inductive logic in Carnap's do not confirm Kemeny's praise of Carnap's achievement (cf. Sterkenburg 2018a, 2018b).
} 
scientific theory; and none of them identified the rationality of science with the use of exclusively formal canons for assessing claims to knowledge. It is misleading to ascribe to all representatives of the "orthodox approach" to the philosophy of science the beliefs that are idiosyncratic of what at best is a relatively small subset of that group of thinkers. (Nagel 1979, p. 3)

This global criticism may be considered an extrapolation of Nagel rejection of Carnap's project of inductive logic. Nagel did not subscribe to a kind of "bipartite metatheory" such as that of Uebel, according to which logical empiricists such as Frank and von Mises on the one side and Carnap on the other side worked on the same project of a comprehensive logical empiricist philosophy of science. ${ }^{12}$ Nagel did not recognize the allegedly possible division of labor between those who dealt with the logical aspects of science and those who concentrated on the empirical aspects. At the end of the day, Nagel considered Carnap's logical way to be misguided and fruitless.

While in his replies to Nagel, Putnam, and Popper in Schilpp (1963) Carnap sharply rejected the criticisms that these authors had put forward against his logic of induction, his replies to Morris, Cohen, and Frank are formulated in more reconciliatory tone. With respect to pragmatism, in rather vague terms he even expressed his gratitude to American pragmatism in general:

\footnotetext{
The influence of the pragmatist ideas has been very fruitful for the development of my conceptions. It did not derive so much from the works of the founders of pragmatism (whose formulations I could often not easily accept, e.g., Peirce's metaphysics and Dewey's discussions of logical and epistemological problems), but from later representatives such as C.I. Lewis, Charles Morris, Ernest Nagel, and Sidney Hook, whose formulations seemed clearer and closer to those customary in science. (Carnap 1963, p. 861)
}

Thereby Carnap elegantly placed himself on the side of rationality and science: Although classical pragmatists such as Peirce and Dewey scientifically left something to be desired, Carnap generously admitted that things had improved with the younger generation of pragmatists. This sounded more like a substantial rapprochement between pragmatism and logical empiricism than it truly was: Actually, it is hard to find any reference to Lewis in

\footnotetext{
${ }^{12}$ Perhaps surprisingly, in Nagel (1979), Neurath and the International Encyclopedia of Unified Science are not mentioned even once, whereas Hempel's account of functional explanation in biology is discussed in detail in the last section of the book.
} 
Carnap's work — with the exception of "Testability and Meaning” (Carnap 1936-37). The same is true for references to Morris, Nagel and Hook. ${ }^{13}$

In any case, the alleged “fruitful influence of pragmatist ideas on [Carnap's] conceptions" was not later acknowledged by Nagel. In contrast, he did not recognize Carnap as a fellow pragmatist. At the end of his philosophical career, Nagel considered Carnap to be representative of an obsolete formalist philosophy of science. On the other hand, Nagel later explicitly sympathized with Frank's Austro-American version of logical empiricism. That is, he did not subscribe to an approach that, much later, Uebel baptized as a "bipartite metatheory" of the philosophy of science to which the members of the left wing of the Vienna Circle subscribed. According to Uebel, Carnap's formal philosophy and science and the more empirically oriented psychological, sociological, and historical works of his fellow Vienna Circle philosophers of science were to be considered two components of a comprehensive "bipartite metatheory" of the philosophy of science. Whatever the virtues of the bipartite metatheory might be, Carnap, as one of its early practitioners, did not convince his "good old friend" Nagel of them.

\subsection{A Role for the History of Science in the Philosophy of Science}

For some time, it has been commonplace knowledge that a good philosophy of science cannot be developed without taking into consideration a good amount of the history of science. ${ }^{14}$ For Nagel, the thesis that the philosophy of science has to take into account the history of science would hardly have been exciting news. For his John Dewey Essays, he chose the title Teleology Revisited and Other Essays in the Philosophy and History of Science. Throughout his career as a philosopher of science, issues of history of science played an important role for him. This holds true particularly for the history of mathematical sciences, which he had pursued since the beginning of his career as a professional philosopher; for details on this, see his “'Impossible Numbers': A Chapter in the History of

\footnotetext{
${ }^{13}$ For instance, the above quotation above is the only one where Carnap mentions the work of Sidney Hook in Schilpp (1963). One of the editors (Tuboly) has pointed out to me that the lack of direct reference to Morris, Nagel, and Hook in Carnap's work leaves open the possibility that these authors "influenced Carnap informally by every-day discussions, joint seminars" and the like. I must admit that I have no idea what this could mean exactly. Rather, I would interpret Carnap's apparently liberal attitude to these and others scholars as a clever strategy designed to appear as a paragon of tolerance and open-mindedness and at the same time pursue his own very specific philosophical projects without paying too much attention to others.

${ }^{14}$ For a discussion of the various ways in which the philosophy and history of science may collaborate in order to provide a better understanding of their common subject, see the introduction of the Festschrift for Michael Friedman Discourse on a New Method-Reinvigorating the Marriage of History and Philosophy of Science edited by Domski and Dickson (2007).
} 
Modern Logic" (Nagel 1935/1979) and "The Formation of Modern Conceptions of Formal Logic in the Development of Geometry" (Nagel (1939/1979).

Nagel's contributions to the philosophy and history of mathematics are still discussed today (cf. for example, Kitcher (2012), Stump (2015), and Blanchette (2017)). The fact that Nagel republished these early pieces in his last book after more than forty years is evidence that he considered them permanently relevant pieces of his philosophical work. ${ }^{15}$

Let us briefly discuss "Impossible Numbers" and compare it with a piece by Carnap written slightly earlier that deals with the issue of "impossible numbers", although of a different kind. Today, the "impossible numbers" Nagel dealt with are just the familiar "complex numbers". They have the form $(\mathrm{a}+\mathrm{ib})$ and appear as roots of polynomials $\mathrm{p}(\mathrm{x}):=$ $a_{n} x^{n}+a_{n-1} x^{n-1}+\ldots+a_{1} x+a_{0}$. From the perspective of modern mathematics, the numbers $(a+$ ib) (in particular their "imaginary parts" ib) are no more mysterious than ordinary "real" numbers Thus, some conceptual effort is required to understand why, for such a long time in the evolution of mathematics, these numbers (and others as well) were considered epistemologically and ontologically dubious.

Traditionally, a "number" is conceived of as being an answer to the question "How many?" and, in cases of extensive measure, "How much?” Evidently, complex numbers cannot be considered reasonable answers to these traditional questions. Consequently, they are "impossible numbers". Negative numbers are difficult to conceive of as answers to questions concerning quantity and extension. On the other hand, "impossible numbers" are undeniably useful. Thus, if mathematics is to be the science of quantity, then complex numbers, not being quantities in any intelligible sense, must be considered "impossible numbers". Thus, it cost mathematicians and philosophers alike a great deal of conceptual effort to understand that mathematics should not be understood as the science of quantity in the traditional sense.

In the following, only "Impossible Numbers" will be treated in some detail. It should be noted, however, that in "The Formation of Modern Conceptions of Formal Logic in the Development of Geometry", Nagel argued for the very same general thesis, namely, that for a more profound understanding of modern science, in particular for the understanding of modern logic and mathematics and that their role in the ongoing development of modern

\footnotetext{
${ }^{15}$ This is confirmed by the following late comment of Nagel, found in Nagel (1979): "[These papers] are the sole fruits of a long since abandoned plan to write a comprehensive history of changes during the 19th century in methodological ideas employed in various branches of inquiry — in the natural, psychological, and social sciences, but also in a number of humanistic disciplines (such as history, legal scholarship, and hermeneutics" (Nagel 1979, p. 318).
} 
science and the history of the sciences is essential. This attitude stands in strong contrast to that of Carnap, who around the same time discussed another kind of "impossible number" but with a quite different attitude than Nagel. Thus, Nagel's philosophy of mathematics was interested in a history of mathematical ideas or concepts that went beyond a mere presentation of their logical relations. More precisely, Nagel argued that some

\footnotetext{
Central doctrines of contemporary logic will become illuminated and made more persuasive by examining the developments in which they terminate. In particular, a consideration of the procedures of mathematics within the historical settings in which they operate may provide materials for a just appraisal of the limitations of traditional conceptions of mathematics and logic, as well as of the more recent views that have replaced them. (Nagel 1979, p. 196)
}

In Carnap's logicist philosophy of mathematics, one does not find anything even remotely similar. From a Carnapian perspective, there was always a strict distinction between a logically correct formulation of a concept, and some logically flawed precursors. The ongoing evolution of science was assumed always to end in "unobjectionable logically precise definitions". An instance of this attitude is provided by Carnap's remarks on infinitesimals as a kind of "impossible number" vividly discussed by many mathematicians and philosophers of mathematics since the end of the $19^{\text {th }}$ century. Carnap gave them short shrift:

\footnotetext{
The inventors of the infinitesimal calculus (Leibniz and Newton) [...] could not say [...] what actually is to be understood by the "derivative" of a function. They could ... not give a precise definition of the concept "derivative". However, their formulations for this definition used such expressions as "infinitesimally small magnitude" [...] turn out to be pseudoconcepts (empty words). It took more than a century before an unobjectionable definition of the general concept of a limit and thus of a derivative was given. Only then all those mathematical results which had long since been used in mathematics were given their actual meaning. (Carnap 1928/1967, pp. 307-308)
}

For Carnap, the history of science did not teach anything to the philosophy of science. This holds even after Carnap came to emphasize the importance of "logical tolerance". This is evidenced by the fact that he completely ignored the logical and philosophical relevance of Robinson's "Non-standard analysis" that offered a logically flawless definition of “infinitesimally small numbers".

In contrast, according to Nagel, we may learn a lot about science from the history of a science. This holds true, in particular, for mathematics. For instance, from the history of 
mathematics we can learn that "[ $\mathrm{t}]$ he proper and exclusive subject matter of mathematics is not quantity", as many philosophers have claimed (Nagel 1935, p. 167). This thesis is elaborated in considerable detail in his papers “"Impossible Numbers': A chapter in the History of Modern Logic" and "The Formation of Modern Conceptions of Formal Logic in the Development of Geometry". The logical empiricists' official "identification" of mathematics and logic, or, more precisely, the "derivation" of the former from the latter, is quite useless in this endeavor. Thus, Nagel's work in the philosophy and history of mathematics goes in a quite different direction than Carnap's logicist approach.

\subsection{Philosophy of Science-Who is the Audience? ${ }^{16}$}

The difference between a logical empiricist philosophy of science and a pragmatist philosophy of science, as exemplified by Carnap and Nagel, should not be conceived of solely as a matter of different personal styles. Rather, it points to a profound difference in how the role of the philosophy of science is understood.

Nagel's account was based on the pragmatist assumption that the task of the philosophy of science is to clarify the broad significance of science for human life. This significance goes beyond the practical control over nature that science yields. Science is more than a set of practically useful technologies. For Nagel, science made the world intelligible. It satisfied the human craving to know and understand, as Aristotle had asserted. ${ }^{17}$ The task of a philosophy of science is to contribute to a "scientific culture", as the Neo-Kantian Cassirer would have said. A Carnapian philosopher of science might not have militated explicitly against this aim, but he or she would have preferred to describe the philosopher's task more theoretically as kind of conceptual engineering directed towards the improvement of the conceptual apparatus of science.

Nagel was an Aristotelian naturalist who considered the desire for knowledge to be an ingredient of human nature. Patrick Suppes, who was Nagel's student and later became one of the most influential philosophers of science of the second half of the $20^{\text {th }}$ century, wrote in a biographical memoir of his teacher:

[What] is most important to emphasize about [Nagel's] more than forty years' association with Columbia University is the central role he played in the intellectual life of Columbia, and more

\footnotetext{
16 The second half of this section's title is borrowed from Kitcher (2019).

${ }^{17}$ Indeed, as Dewulf (2018, pp. 156-157) recently argued convincingly, Nagel's philosophy of science may be characterized as a kind of Aristotelian philosophy of science. See also Dewulf's contribution to this volume.
} 
generally, of New York City. To many students he was the outstanding spokesman of what philosophy could offer in terms of the analysis of the scientific method, as it is practiced in many different sciences, and in the relation between science and perennial problems of philosophy such as those of causality and determinism. [...]

[...] Throughout his career Nagel tried to combine the best elements of Cohen's philosophical realism and Dewey's radical instrumentalism. [...] It is fair to say that the range of his scientific interests and knowledge exceeded that of any other philosopher of science of his generation in the United States. (Suppes 1994, pp. 258-259) ${ }^{18}$

Nagel's role as a philosopher of science, as described by Suppes, was quite different from the Carnapian model of the philosopher as a linguistic engineer engaged in the construction of conceptual apparatuses that work in an optimal way for some purpose or other. Without denying the existence of far-reaching differences between their philosophical convictions, philosophers such as Nagel, Lewis, Dewey, and even Rorty should be grouped in a different class of philosophers from the conceptual engineer Carnap, who more resembled a player of Hesse's glass bead game than a pragmatist committed to the actual world. ${ }^{19}$ For Carnap, societal praxis remained a matter of private commitment, so to speak. Nagel's praxis of a professional philosopher of science relied on a quite different idea. ${ }^{20}$

Natural, although somewhat embarrassing, questions for many philosophers of science are "What is the philosophy of science good for?", "Who is the audience of the philosophy of science?", or "To whom is the philosophy of science addressed?" (cf. Kitcher 2019). Kitcher proposed three possible answers: "Philosophers, scientists, and interested citizens within and beyond the academy. I argue that our discipline is potentially relevant to all three, but I particularly press the claims of the interested citizens" (Kitcher 2019, p. 1).

Obviously, for a Carnapian conceptual engineer, the educated citizen is not the first addressee. Scientific engineering aims to improve the conceptual apparatus of the sciences. Whether this kind of logical philosophy of science actually has been relevant to scientists can be doubted as well. Be this as it may, Nagel's way of doing the philosophy of science came

\footnotetext{
${ }^{18}$ Further information about Nagel as a leading figure in the philosophical and cultural life of New York can be found in Jewitt (2012) and Dewulf (2018).

${ }^{19}$ This is not to deny that Carnap personally showed much social commitment, but this commitment was not founded in his theoretical convictions as a professional philosopher of science. Expressed in a somewhat unfriendly way, the "boundless ocean of possibilities" that he evoked emphatically in The Logical Syntax of Language (Carnap 1937) may have some features in common with Hesse's Glass Bead Game (1943/2002). There are some authors who would strongly reject such a suspicion, see for instance Carus's book Carnap and Twentieth-century Thought: Explication as Enlightenment (Carus 2007) where Carnap's philosophy is praised enthusiastically as the outstanding paradigm of a radically modern enlightenment philosophical position "strikingly relevant in 21 . century".

${ }^{20}$ For this aspect of Nagel's philosophy see Eric Schliesser's contribution to this volume.
} 
rather close to Kitcher's comprehensive idea of the discipline.

\subsection{Concluding Remarks}

In the 1930s, Nagel's role in the ongoing encounter between logical empiricism and American pragmatism can be accurately described as a committed mediator and bridge builder between the two movements. In later years, this description is no longer true. Nagel's negative assessment of Carnap's later philosophy (first, his account of probability and inductive logic and later, his approach in its entirely) shows that for Nagel, the much-evoked convergence between logical empiricism and American pragmatism had not taken place. ${ }^{21}$

Nagel's rejection of Carnap's logical approach cannot be misunderstood as the reaction of a philosopher who was simply unable to understand formal arguments. Rather, Nagel rejected Carnap's philosophy as an ultimately non-pragmatist way of doing philosophy that did not take into account (or even explicitly rejected) the fundamental connection of knowledge, action and valuation that the pragmatist Lewis expressed in a concise way as follows:

\footnotetext{
Knowledge, action, and evaluation are essentially connected. The primary and pervasive significance of knowledge lies in its guidance of action; knowing is for the sake of doing. And action, obviously, is rooted in evaluation. For a being which did not assign comparative values, deliberate action would be pointless; and for one which did not know, it would be impossible. Conversely, only an active being could have knowledge, and only such a being could assign values to anything beyond his own feelings. (Lewis 1946, p. 5)
}

Despite paying lip-service to the contrary, hard-boiled logical empiricists such as Carnap never acknowledged this connection without caveats. This attitude rendered impossible a close relationship between Carnapian logicist empiricism and American genuine pragmatism.

\subsection{References}

Blanchette, P. (2017). Models in Geometry and Logic: 1870-1920. In H. Leitgeb, P. Seppala, I. Niniiluoto (eds.), Logic, Methodology and Philosophy of Science: Proceedings of the 15th International Congress. College Publications, 41-61.

\footnotetext{
${ }^{21}$ This fact does not exclude that there have been logical empiricists, who may be said to have "converged" or "drifted" to pragmatism, e.g., Frank and Hempel (cf. Mormann 2017 and Wolters 2003); see also Frank (2021).
} 
Carnap, R. (1928/1967). The Logical Construction of the World and Pseudoproblems in Philosophy, Chicago and LaSalle: Open Court.

Carnap, R. (1936-37). Testability and Meaning. Philosophy of Science 3 (4): 419-471, and 4 (1): $166-188$.

Carnap, R. (1937). The Logical Syntax of Language. London: Routledge.

Carnap, R. (1942). Introduction to Semantics. Cambridge, MA.: Harvard University Press.

Carnap, R. (1950). Empiricism, Semantics, and Ontology. Review Internationale de Philosophie 4 (11): 20-40.

Carnap, R. (1963). Ernest Nagel on Induction. In P.A. Schilpp (ed.), The Philosophy of Rudolf Carnap. LaSalle and Chicago: Open Court, 989-995.

Carus, A.W. (2007). Carnap and Twentieth-Century Thought: Explication as Enlightenment. Cambridge: Cambridge University Press.

Cat, J., and Tuboly, A.T. (eds.) (2019). Neurath Reconsidered: New Sources and Perspectives. Cham: Springer.

Cohen, R.S. (1963). Dialectical Materialism and Carnap's Logical Empiricism. In P.A. Schilpp (ed.), The Philosophy of Rudolf Carnap. Chicago and LaSalle: Open Court, 99158.

Dahms, H-J. (1999). Otto Neuraths “International Encyclopedia of Unified Science” als Torso. In E. Nemeth, R. Heinrich (eds.), Otto Neurath: Rationalität, Planung, Vielfalt, Wien: Oldenbourg, 184-227.

Dewulf, F. (2018). A Genealogy of Scientific Explanation: The Emergence of the DeductiveNomological Model at the Intersection of German Historical and Scientific Philosophy. $\mathrm{PhD}$ Thesis of the University of Ghent, Belgium.

Domski, M., and Dickson, M. (eds.) (2010). Discourse on a New Method, Revigorating the Marriage between History and Philosophy of Science, Chicago and LaSalle: Open Court.

Frank, Ph. (1949). Modern Science and its Philosophy. Cambridge MA.: Harvard University Press.

Frank, Ph. (2021). The Humanistic Background of Science. Edited by G. Reisch and A.T. Tuboly. New York: SUNY Press.

Hesse, H. (1943/2002). The Glass Bead Game, New York: Picador.

Jewett, A. (2011). Canonizing Dewey: Naturalism, Logical Empiricism, and the Idea of American Philosophy. Modern Intellectual History 8: 91-125.

Jewett, A. (2012). Science, Democracy, and the American University. From the Civil War to 
the Cold War. Cambridge: Cambridge University Press.

Kitcher, P. (2012). Preludes to Pragmatism. Toward a Reconstruction of Philosophy, Oxford: Oxford University Press.

Kitcher, P. (2019). So ... who is your audience? European Journal for Philosophy of Science 9 (1): $1-15$.

Lewis, C.I. (1946). An Analysis of Knowledge and Valuation. Chicago and LaSalle: Open Court.

Limbeck-Lilienau, Ch. (2012). Carnap's encounter with pragmatism. In R. Creath (ed.), Rudolf Carnap and the Legacy of Logical Empiricism. Dordrecht: Springer, 89-110.

Misak, C. (2013). The American Pragmatists. Oxford: Oxford University Press.

Mormann, Th. (1991). Neuraths Enzyklopädismus: Entwurf eines radikalen Empirizismus. Journal of General Philosophy of Science 22 (1): 73-100.

Mormann, Th. (2017). Philipp Frank's Austro-American Logical Empiricism. HOPOS: The Journal of the International Society for the History of Philosophy of Science 7 (1): 5686.

Morris, C.W. (1937). Logical Positivism, Pragmatism and Scientific Empiricism. Paris: Hermann.

Nagel, E. (1935/1979). 'Impossible Numbers': A Chapter in the History of Modern Logic. In Nagel (1979): 166-194.

Nagel, E. (1939/1979). The Formation of Modern Conceptions of Formal Logic in the Development of Geometry. In Nagel (1979): 195-259.

Nagel, E. (1940). Charles S. Peirce: A Pioneer of Modern Empirism. Philosophy of Science 7 (1): 69-80.

Nagel, E. (1942). Review of R. Carnap, Introduction to Semantics. Journal of Philosophy 39 (17): 468-473.

Nagel, E. (1963). Carnap's Theory of Induction. In P. A. Schilpp (ed.), The Philosophy of Rudolf Carnap. Chicago and LaSalle: Open Court, 785-826.

Nagel, E. (1979). Teleology Revisited and Other Essays in the Philosophy and History of Science. New York: Columbia University Press.

Peirce, C.S. (1976). The New Elements of Mathematics, Volume 4, Mathematical Philosophy, edited by Carolyn Eisele, The Hague and Paris, Mouton Publishers.

Reisch, G.A. (2005). How the Cold War Transformed Philosophy of Science. To the Icy Slopes of Logic. New York: Cambridge University Press.

Richardson, A. (2007) Carnapian Pragmatism. In M. Friedman and R. Creath (eds.), The 
Cambridge Companion to Carnap. Cambridge: Cambridge University Press, 295-315.

Rorty, R. (1995). Response to Richard Bernstein. In H.J. Saatkamp Jr. (ed.), Rorty and

Pragmatism: The Philosopher Responds to his Critics. Nashville, Vanderbilt University Press, 68-71.

Soames, S. (2008). Analytic Philosophy in America. In Ch. Misak (ed.), The Oxford Handbook of American Philosophy. Oxford, Oxford University Press: 449-481.

Sterkenburg, T.F. (2018a). Universal Predictio: A Philosophical Investigation. PhD-Thesis, University of Groningen, The Netherlands.

Sterkenburg, T.F. (2018b). Putnam's diagonal argument and the impossibility of a universal learning machine. Erkenntnis 84 (3): 633-656.

Stump, D.J. (2015). Conceptual Change and the Philosophy of Science. Alternative Interpretations of the A Priori. New York and London: Routledge.

Suppes, P. (1994). Ernest Nagel, 1901-1986: A Biographical Memoir. The National Academy of the Sciences: 257-272.

Tuboly, A.T. (2021). To the Icy Slopes in the Melting pot: Forging Logical Empiricisms in the Contexts of American Pragmatisms, HOPOS: The Journal of the International Society for the History of Philosophy of Science 11 (1). Forthcoming.

Uebel, Th. (2012). The Bipartite Conception of Metatheory and the Dialectical Conception of Explication. In P. Wagner (ed), Carnap's Ideal of Explication and Naturalism. Basingstoke: Palgrave MacMillan, 117-130.

Uebel, Th. (2016). American Pragmatism and the Vienna Circle: The Early Years. Journal for the History of Analytical Philosophy 3 (3): 1-35.

Wolters, G. (2003). Carl Gustav Hempel, Pragmatic Empiricist. In P. Parrini, W.C. Salmon, and M.H. Salmon (eds.), Logical Empiricism. Historical and Contemporary Perspectives, Pittsburgh: University of Pittsburgh Press, 109-122. 